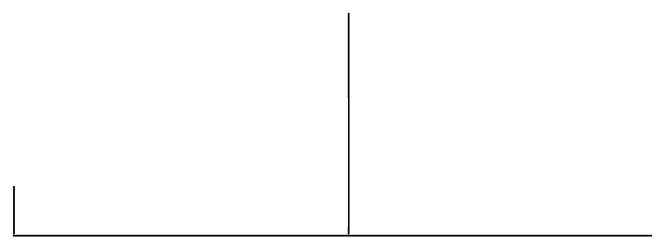

Rev. Latinoam. Psicopat. Fund., São Paulo, v. 15, n. 2, p. 364-381, junho 2012

\title{
As origens do alienismo no Brasil: dois artigos pioneiros sobre o Hospício de Pedro II
}

\author{
Manoel Olavo Loureiro Teixeira \\ Fernando A. de Cunha Ramos
}

O artigo discute dois trabalhos que, de forma pioneira, descreveram o funcionamento do Hospício de Pedro II, primeira instituição psiquiátrica do Brasil: L'hospice Pedro II et les Alienés au Brésil, de Phillipe-Marius Rey (1875); e Visite a L'sile de Pedro II a Rio de Janeiro, de François Jouin (1880). O contexto histórico de criação do hospício e seu funcionamento inicial são analisados. Sua construção é correlacionada à afirmação política do Segundo Reinado. Aspectos referentes à organização do alienismo no país e às características raciais da sociedade brasileira são abordados.

Palavras-chave: Hospício de Pedro II, alienismo, história da psiquiatria no Brasil, narrativas de viagem 


\section{A construção do Hospício de Pedro II}

O marco institucional fundador do alienismo brasileiro é a inauguração do Hospício de Pedro II, em 1852, na cidade do Rio de Janeiro, então sede da Corte Imperial. Para dimensionar a importância desta criação, basta lembrar que o decreto n. 82 , de 18 de julho de 1841, determinando essa fundação, foi o primeiro decreto assinado pelo Imperador no dia da sua coroação.

A construção do hospício, no bairro da Praia Vermelha, leva mais de dez anos. Seu desenho arquitetônico inspira-se na Maison Nationale de Charenton, na França. O edifício de linhas neoclássicas é decorado com sete estátuas feitas pelo escultor alemão Ferdinand Petricch: de Dom Pedro II; de José Clemente Pereira, provedor da Santa Casa que coordena a construção; dos alienistas Phillipe Pinel e Étienne Esquirol; das deusas Ciência e Caridade; e de São Pedro de Alcântara, padroeiro do Império brasileiro. O hospício, planejado inicialmente para comportar 300 pacientes, é concebido como um grande retângulo, enquadrando quatro grandes pátios internos, separados por um corpo central. Há duas alas, uma masculina e outra feminina: respectivamente, as alas Pinel e Esquirol. Cada ala divide-se em três classes de pacientes: a primeira, a segunda e a terceira classe, todas elas pagas. Excepcionalmente, por decisão do provedor da Santa Casa, indigentes são admitidos gratuitamente. No centro da construção, em destaque, fica a capela (Teixeira, 1998; Teixeira e Silva Filho, 2008; Lopes, 1939).

Primeiro manicômio ao sul da linha do Equador, primeiro hospício da América Latina e principal realização pública do Império no período, o grandioso estabelecimento, chamado de "Palácio da Praia Vermelha", desponta como um símbolo de modernidade do Império brasileiro. Um Império sul-americano, continental, tropical, mestiço, de população rala, de origem majoritariamente negra e indígena, com uma sociedade predominantemente rural, uma economia baseada na manufatura cafeeira sustentada pelo trabalho escravo, quase esfacelado pela crise política e por 29 levantes separatistas regionais durante o período da Regência (1831-1840). 


\section{O papel simbólico do Hospício e o Segundo Reinado}

Com o advento do Segundo Reinado, na década de 1840, o Império brasileiro busca organizar-se pelo fortalecimento de um poder central, ao fim do tumultuado período da Regência. Do ponto de vista histórico, o Segundo Reinado representa um terceiro e decisivo degrau no processo de consolidação da nação brasileira. O primeiro ocorre em 1815, quando o Príncipe Regente Dom João eleva o Brasil à condição de Reino Unido a Portugal e Algarves. Iniciativa que fracassa quando a Revolução Constitucionalista do Porto força a família real a retornar a Lisboa, desenvolvendo-se um projeto de recolonização do Brasil (Costa, 1998).

O segundo degrau ocorre com a declaração de independência, em 1822, e o início do conturbado reinado de Pedro I. Este fracassa, em 1831, com a abdicação de Pedro I, em meio ao fragor de um levante popular. O Segundo Reinado, encarnado na figura do jovem Imperador Dom Pedro II, coroado aos 15 anos, após a antecipação de sua maioridade, representa assim uma terceira tentativa de consolidação do Estado brasileiro, que não poderia fracassar. Era fundamental um enorme esforço de estabilização e centralização político-institucional do País.

O Hospício de Pedro II, engastado como joia rara na entrada da Baía de Guanabara, isto é, na entrada da capital do Império, representa a fortaleza simbólica que garante ao país a estabilidade e coesão necessárias ao enfrentamento das forças desagregadoras presentes tanto na irracionalidade do jogo político quanto na loucura dos governantes. Na sua missão simbólica de afirmar o valor cultural da nação brasileira, o hospício de Pedro II desempenha dois papéis convergentes. De um lado, de forma óbvia e explícita, o hospício oferece uma demonstração clara de que no Brasil se cultiva a ciência. De outro, de forma implícita e aparentemente paradoxal, comprova que o Brasil é capaz de produzir loucos.

No que diz respeito ao primeiro papel, a criação do Hospício de Pedro II coincide com o período que se segue à promulgação da Lei de 30 de junho de 1838, na França, a qual colocou os asilos de alienados na posição de vanguarda da medicina hospitalar da época. Portanto, exibir um asilo de alienados, em meados do século XIX, era a prova cabal da modernidade científica e tecnológica de uma nação. É nesse período que o continente europeu, sob a liderança e domínio cultural da França, vive o esplendor do que Robert Castel chama de "Idade de Ouro" do alienismo (Castel, 1978).

Quanto ao segundo papel, é importante lembrar que, no contexto do alienismo da época, que valoriza as causas morais da loucura, era a civilização - com suas complexidades, excessos e reveses - que representava a principal 
fonte de adoecimento mental. De modo que possuir loucos era um apanágio dos países civilizados. Esquirol, no seu verbete Folie, publicado no Dictionnaire de Sciences Médicales, ao falar da nação inglesa, então em avançado processo de industrialização, afirma que "na Inglaterra, onde se encontram reunidas todas as vicissitudes, todos os excessos da civilização, a loucura é mais frequente que em todos os outros lugares" (Esquirol, 1816, p. 180).

Desta forma, o Hospício de Pedro II funciona como um farol simbólico que anuncia ao Ocidente a participação do Brasil no mundo civilizado da época. Uma nação suficientemente evoluída, tanto na sua capacidade de produzir loucos, quanto na sua capacidade de tratá-los com os recursos da ciência moderna.

\section{O alienismo, aqui e além-mar}

O alienismo, que surge na virada do século XVIII para o século XIX, representa a resposta da ciência médica à questão da loucura, redescrita como alienação mental - isto é, como uma doença que deveria ser tratada por um tipo especial de medicina, segundo os paradigmas do tratamento físico-moral pineliano e da teoria das paixões. A loucura passa a ser entendida como uma afecção médica provocada pela combinação de causas físicas e morais. Neste contexto, aparece um novo especialista, o alienista, a quem compete tratar, usando uma expressão da época, "dos infelizes privados do uso da razão". Aparece também o hospício, lugar de triunfo e operação desta nova concepção.

O nascente alienismo busca retirar a loucura do terreno das especulações metafísicas e religiosas, apresentando-se como uma alternativa mais moderna e humanitária ao cuidado religioso oferecido aos loucos europeus por diversas irmandades religiosas e hospitais de caridade. Phillipe Pinel, com a experiência de Bicêtre e Salpètriére e a publicação do Tratado Médico Filosófico sobre a Alienação Mental (1801), personifica o modelo de intelectual-cientista do campo do alienismo. Mais que um modelo, é o seu mito fundador.

No Brasil, entretanto, o Hospício de Pedro II nasce submetido a uma gestão religiosa. O Império brasileiro é oficialmente católico. O hospício é subordinado à Santa Casa de Misericórdia do Rio de Janeiro, administrado por seu provedor-geral e conduzido por freiras da Ordem de São Vicente de Paulo. Na Europa, o hospício nasce como tradução de uma nova ordem liberal, no contexto da Revolução Francesa. No Brasil, o hospício nasce como símbolo de restauração política, num regime monárquico conservador, centralizado e escravocrata, no qual a separação entre Estado e Igreja ainda não se dera. 


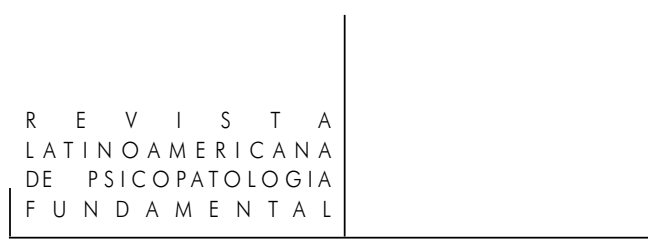

\section{As primeiras décadas de funcionamento hospitalar}

Apesar do começo pouco medicalizado, o Hospício de Pedro II cumpre sua função simbólica inicial, tornando-se parada obrigatória para todas as figuras de destaque que visitam o Rio de Janeiro. O hospício passa a ter lugar garantido nas coleções de gravuras retratando os monumentos do Rio de Janeiro e nos mapas turísticos da cidade (Bertichem, 1976). No rastro dessa tendência, o naturalista suíço Louis Agassiz relata o deslumbramento do seu primeiro contato com o Hospício de Pedro II. No livro A Journey in Brazil, escrito em colaboração com sua esposa Elizabeth, Agassiz descreve a viagem realizada no território brasileiro nos anos 1865-1866. Assim o casal descreve seu contato inicial com o hospício, durante um passeio pela enseada de Botafogo:

O caminho nos levou a um magnífico hospício de alienados, o Hospício de Pedro II, o qual havíamos visto e admirado do convés do navio logo no dia de nossa chegada. [...] É difícil imaginar uma construção mais apropriada para a finalidade a que se destina. (Agassiz, 1869, p. 81)

Mais adiante, ao visitar a capela do hospício, Elizabeth Agassiz relata:

As velas ardiam diante do altar, mas a enorme janela, situada logo na saída da porta, abria-se para o sol poente, e, enquanto permanecia na sacada, contemplando as montanhas e apreciando a música, me veio o pensamento de que uma mente extraviada poderia reencontrar o caminho de volta em meio a tais cenários e influências. Certamente, se a natureza possuía algum poder de cura, este só poderia ocorrer em um lugar como aquele. (p. 82)

Ou seja, se havia algo capaz de curar a loucura no Hospício de Pedro II, em meados dos anos 1860, o crédito devia ser dado à natureza, não à ciência.

\section{$O$ confronto entre ciência e religião}

Após sua inauguração, o Hospício de Pedro II funciona, por largo período, como um hospital geral europeu do século XVIII: uma instituição para o acolhimento de doentes, órfãos e desenganados de toda sorte, com um funcionamento caritativo e religioso e apenas secundariamente medicalizado. Seus primeiros 45 anos de funcionamento são marcados pelo conflito de autoridade entre médicos e religiosos. Embora o hospício tivesse diretores médicos e dois facultativos exclusivos, na prática, o poder administrativo era exercido pelas freiras da Ordem de São Vicente de Paulo e pelos enfermeiros a elas subordinados.

Rev. Latinoam. Psicopat. Fund., São Paulo, v. 15, n. 2, p. 364-381, junho 2012 
Os médicos, alijados do efetivo poder administrativo, travam uma batalha de quase quatro décadas contra esse estado de coisas. Atacam o funcionamento do hospício e reivindicam a parcela de poder que lhes parecia justa: isto é, todo ele. O debate ocupa as páginas dos jornais e publicações não médicas. O hospício é chamado de lugar onde "a arte e a beleza tinham esquecido a ciência", de "ser mais parecido com um convento que com um hospital”. A solução proposta é a laicização do hospício, sua desvinculação administrativa da Santa Casa e a passagem do poder aos alienistas, os únicos aptos a aplicar os princípios do tratamento moral.

\section{O alienismo brasileiro busca sua maioridade}

Os anos 1870 representam um divisor de águas para o Império. O fim da guerra do Paraguai marca um acelerado processo de desenvolvimento, mas também o início de novas tensões sociais. Movimentos sociais, como o Abolicionismo e o Republicanismo, passam a agitar as camadas médias da sociedade, as quais, finalmente, despontam e se afirmam em meio a uma sociedade fortemente dividida entre senhores e escravos. Uma parte importante dessa classe média incipiente é constituída por profissionais liberais, formados nos colégios e faculdades do Segundo Reinado. No Rio de Janeiro, sede da principal faculdade de medicina, os médicos conquistarão influência destacada. Torna-se indispensável um lugar efetivo de exercício e de poder para o novo ramo especial da medicina, o alienismo. É na década de 1870 que se formam, na faculdade de medicina do Rio de Janeiro, três personalidades decisivas para a história da psiquiatria no Brasil: em 1875, Nuno Ferreira de Andrade; e, em 1877, João Carlos Teixeira Brandão e Carlos Fernandes Eiras.

Os projetos dos novos alienistas eram basicamente quatro: primeiramente, a ampliação e modernização da estrutura física e dos equipamentos do Hospício de Pedro II; em segundo lugar, sua completa medicalização, com o aumento e especialização do corpo clínico e a obtenção, por parte dos médicos, do pleno poder administrativo sobre a instituição; em terceiro, o estabelecimento de um alienismo acadêmico, mediante a criação de uma cátedra dedicada às moléstias mentais na Faculdade de Medicina e de cursos regulares de clínica psiquiátrica no hospício; e, por fim, a ampliação da prática privada dos alienistas, com o surgimento de novas casas de saúde dedicadas ao tratamento de doentes mentais e de atendimento de consultório. Dois jovens alienistas representativos desse período são Nuno Ferreira de Andrade, que assumirá a liderança do projeto público-acadêmico e Carlos Fernandes Eiras, que conduzirá o projeto privado-liberal. 
Os dados biográficos de Nuno de Andrade indicam que ele projetou alcançar, desde muito cedo, o lugar de primeiro alienista brasileiro. Sua tese de graduação, em 1875, teve como tema Do Diagnóstico e Tratamento das Nevroses Viscerais. Em 1876, Andrade apresenta à Academia Imperial de Medicina, visando obter o lugar de membro-titular, uma memória intitulada Da Natureza e do Diagnóstico da Alienação Mental. Nesse texto, Nuno de Andrade emite um parecer referindo-se à consulta dirigida à Academia Imperial de Medicina pelo cidadão Alexandre da Costa Silveira, preso em novembro de 1875 e, em seguida, recolhido ao hospício por atos de desordem pública. Silveira somente obteve o reconhecimento de sua sanidade mental em março de 1876, após ter ficado "privado de sua liberdade por suposta loucura durante 115 dias" (Rego Filho, 1879, p. 98). O caso transformara-se numa polêmica pública.

Em 1877, Nuno de Andrade torna-se médico adjunto do Hospício de Pedro II (Almanak Laemmert, 1877, p. 524), função criada pela administração da Santa Casa após muita insistência por parte dos médicos diretores do hospício. Andrade também tenta produzir material didático para um curso de patologia mental que pretendia iniciar. Era urgente introduzir-se o ensino da psicopatologia nas faculdades de medicina, e Nuno de Andrade prepara-se para ser pioneiro nesse ensino. No entanto, havia uma pedra maior no caminho, a saber: a resistência da administração da Santa Casa de Misericórdia em permitir a entrada de estudantes no Hospício de Pedro II.

Nuno de Andrade permanece na função de médico-adjunto do hospício até 1878, deixando-a em seguida. Para vencer a oposição da administração da Santa Casa, com uma ação capaz de chegar aos ouvidos do Imperador Pedro II, Andrade apela ao Barão do Lavradio, presidente da Academia Imperial de Medicina e principal autoridade médica do período. O Barão pronuncia um discurso na Academia Imperial de Medicina, em 30 de junho de 1878, defendendo a necessidade do estudo das moléstias mentais e a criação de uma cadeira de ensino da matéria (Rego, 1878). No discurso, ouvido pelo próprio Imperador, o Barão exalta a iniciativa pioneira de Nuno de Andrade.

Em abril de 1879, nove meses após o discurso do Barão, a Reforma Leôncio de Carvalho, que reorganiza o ensino no Império, ${ }^{1}$ cria a tão esperada cadeira de clínica psiquiátrica nas faculdades de medicina do Império. Em 1881, Nuno de Andrade é nomeado lente interino da cadeira de psiquiatria. Três meses depois, é nomeado diretor geral do Hospício de Pedro II, função que exerce entre 1881 e 1882. Durante esse período, propõe ao provedor e conselheiro Visconde de Jaguary a separação do hospício da Santa Casa de Misericórdia e faz inúmeras

1. Cf. Decreto $\mathrm{N}^{\circ} 7247$, de 19 de abril de 1879 . 
denúncias contra os religiosos. Nuno de Andrade entra em confronto aberto com a administração da Santa Casa. Ao fim de uma conturbada crise, Andrade é demitido da direção do hospício. Também é demitido da cátedra de moléstias mentais, sendo substituído por Souza Lima.

Souza Lima, por sua vez, é sucedido na cátedra, em 1883, pelo jovem alienista de 29 anos, João Carlos Teixeira Brandão, polemista da imprensa, militante republicano e primeiro brasileiro membro-associado da Sociedade Médico-Psicológica de Paris. Teixeira Brandão torna-se o primeiro titular da cadeira de clínica psiquiátrica aprovado por concurso público, conforme determinava a lei n. 3141 de 1882. Em 1883, Teixeira Brandão é nomeado médico do hospício. Em 1887, já nos estertores da Monarquia, é nomeado diretor do Hospício de Pedro II pelo Barão de Cotegipe, presidente do Conselho de Ministros e seu protetor.

Em 1890, após a proclamação da República, o hospício é finalmente desanexado da Santa Casa de Misericórdia, pelo decreto lei 142-A. Teixeira Brandão, um militante histórico do movimento republicano, é mantido na direção do agora chamado Hospício Nacional dos Alienados, exercendo o cargo entre 1887 e 1892. Com a ascensão de Teixeira Brandão à direção do hospital, na aurora da República brasileira, inicia-se a tardia medicalização do antigo Hospício de Pedro II.

\section{A questão racial brasileira}

Outro aspecto a ser destacado no contexto da época é a composição racial da sociedade brasileira, em relação à ciência da segunda metade do século XIX. O Brasil do século XIX mostra uma rígida divisão social entre uma elite de proprietários rurais, de origem portuguesa - frequentemente mestiça, mas autodenominada branca - e uma imensa maioria de população negra e mestiça, historicamente destinada ao trabalho braçal escravo e tratada como categoria subumana. A partir da década de 1850, o Segundo Império da França é adotado pelo Império brasileiro como um modelo a ser seguido, num francesismo que incluía, além da cópia das modas, modismos, artes e urbanização de Paris, a adoção das principais correntes de pensamento da França, em sintonia com o ideário triunfante da ciência no século XIX.

É justamente quando tomam corpo no cenário intelectual europeu as teorias raciais evolucionistas de autores como Gobineau, Agassiz e Buckle, que assinalam a inferioridade constitucional dos negros e indígenas e, principalmente, a inviabilidade e a inexorável tendência à degeneração de populações constituídas por raças miscigenadas. Surge no Brasil uma crescente preocupação com a 
constituição racial de sua sociedade, com o fato de sermos um país despovoado, habitado por uma população considerada inferior. $\mathrm{O}$ ideário das teorias raciais é adotado entre nós. Lastimam-se os chamados "infortúnios da miscigenação". A elite intelectual brasileira - os "homens da sciencia" do Segundo Reinado - fica convencida que não tínhamos um povo à altura de seu projeto de modernização, agora contando com um discurso científico que referenda essa percepção. ${ }^{2}$

É o momento em que se pensa a criação de alternativas econômicas para uma possível ausência da mão de obra escrava, pois o fim da escravatura mostra-se inevitável. A importação de imigrantes brancos europeus aparece como uma alternativa que, ademais, iria promover o embranquecimento e o aprimoramento racial da população. Tudo isto contribui para a grande imigração européia ao Brasil da segunda metade do século XIX.

\section{Dois artigos pioneiros}

O levantamento das fontes primárias mostra que não foram escritos trabalhos científicos sobre o Hospício de Pedro II nos primeiros 25 anos de funcionamento. Dois textos merecem destaque por seu pioneirismo: os artigos de Philippe-Marius Rey, "L’hospice Pedro II et les Alienés au Brésil (1875)" e de François Jouin, "Visite a L'asile de Pedro II a Rio de Janeiro (1880)" - traduzidos e publicados nesta edição da Revista Latinoamericana de Psicopatologia Fundamental.

Da mesma maneira que os naturalistas europeus faziam expedições e produziam descrições de nossa riqueza, miséria e exotismo a partir do século XVIII, os primeiros trabalhos científicos a descrever e analisaro Hospício de Pedro II foram escritos em francês, por visitantes estrangeiros: no caso, por dois alienistas franceses, de passagem pelo Rio de Janeiro. Os artigos são publicados nos Annales Médico-Psychologiques, na sessão que descreve, a cada edição, os hospícios de diferentes partes do mundo. Ambos criticam o caráter religioso e secundariamente medicalizado do hospício; defendem os colegas médicos brasileiros e são marcados por um olhar etnográfico, que lança luzes sobre a maneira como o conflito identitário brasileiro se apresenta nos corredores, pátios e salões de pé-direito alto do hospício de Pedro II.

2. Para aprofundamento do tema, vide Schwarcz, 1998. 
O trabalho "L'hospice Pedro II et les alienés au Brésil", de Phillipe Rey, médico interno ${ }^{3}$ do Asilo de Saint-Anne, resulta de sua estadia de trinta dias no hospício. Ele exalta a beleza arquitetônica, mas critica seu funcionamento e atraso científico. Diz que as celas-fortes são primitivas e lembram os piores tempos da história dos asilos (Rey, 1875, p. 77). Critica a falta de médicos permanentemente lotados no hospital, lamenta o fato de o hospício ficar, durante boa parte do tempo, entregue à madre superiora. Sugere a criação da função de médico interno no hospital e propõe o oferecimento do encargo a estudantes da faculdade de medicina. A visita de Rey ocorre no momento em que o hospício está sendo ampliado, com a criação de um primeiro andar reservado aos doentes tranquilos. Os doentes agitados permaneceriam no andar térreo. O trabalho registra essa tentativa de mudança arquitetônica em função de critérios diagnósticos. No artigo, Rey defende a ampliação do número de asilos no país, o que reduziria a superlotação. Como porta-voz do alienismo, sugere a expansão do alcance institucional de sua especialidade.

O artigo também organiza material estatístico retirado dos relatórios dos diretores médicos de 1869-1870 e 1873-1874. A população de internos analisada é dividida entre livres, libertos e escravos. Dois aspectos chamam a atenção nos dados: 1) o baixo percentual de escravos e libertos; e 2) o alto percentual de estrangeiros, principalmente imigrantes europeus, entre a população internada no hospício - provavelmente relacionado à grande imigração da segunda metade do século XIX. Entre os diagnósticos psiquiátricos mais frequentes, Rey destaca: a demência, a mania, a monomania, a lipemania, o alcoolismo, a imbecilidade, a histeria e a paralisia geral. Entretanto, Rey questiona a validade desses dados, pois os médicos do Hospício de Pedro II, em suas palavras, "adotam uma classificação inusitada, na qual as alucinações, a exaltação maníaca e a mania periódica são relatadas como formas particulares. Além disso, uma grande parte dos pacientes permanece sem diagnóstico" (1875, p. 94).

O modo como Rey aborda o cardápio diário dos internos do hospital é interessante. Ele descreve o cardápio dos pensionistas de primeira e segunda classe com um requinte à européia e lança um olhar de estranheza sobre o cardápio servido aos pensionistas de terceira classe e indigentes, que inclui o uso de carne-seca, feijão e farinha de mandioca. Rey parece surpreender-se com o fato de este cardápio ser preferido entre certos pacientes, em vez do outro.

3. O internato era um período de especialização, feito em hospital, por médicos recém-formados. Equivale à atual residência médica. 
O artigo se encerra com a afirmação de que, embora a organização do serviço interno do hospício deixe a desejar, os médicos brasileiros possuíam um conhecimento profundo das reformas necessárias e dos tratamentos aplicados aos alienados. Rey deixa claro que, no seu entender, os médicos eram os verdadeiros detentores do conhecimento sobre as reformas a serem implantadas no hospício de Pedro II. Em mais de uma passagem, o texto estabelece uma contraposição entre o que Rey chama de "espírito do progresso científico", versus o "espírito da rotina, ou da caridade". Um embate entre ciência e religião. O que fica sugerido nas entrelinhas é a necessidade da laicização do hospício e sua administração por alienistas, os legítimos representantes da ciência e do progresso: um tema caro aos interesses do corpo médico de então.

\section{Jouin: mestiçagem e elemento racial}

O artigo "Visite a l'asile de Pedro II a Rio de Janeiro", de François Jouin, é resultado de sua viagem como médico a bordo de um vapor, quando visita hospícios de Buenos Aires, Montevidéu e Rio de Janeiro. A estadia no Brasil é curta e o trabalho reflete o impacto de suas impressões iniciais. Jouin faz muitas especulações, ao contrário de Rey, cujo texto é mais organizado e tem maior profundidade de análise.

Como outros visitantes, Jouin exalta a suntuosidade arquitetônica do hospício. Não critica diretamente o funcionamento asilar, assinalando que o diretor médico Gustavo Balduíno de Moura e Câmara o mantém "sob sua imediata supervisão e em perfeito funcionamento" (Jouin, 1880, p. 248). Seu relato passa ao largo da grave disputa entre médicos e religiosos que ali se desenrola. $\mathrm{O}$ artigo de Jouin defende a administração, sublinha o interesse científico e reforça a posição política do diretor Moura e Câmara, seu guia durante a visita - que, aliás, seria demitido do cargo no ano seguinte à publicação do artigo, sendo sucedido por Nuno de Andrade.

No artigo, Jouin destaca a importância da relação entre a loucura e as raças humanas como um dado semiológico não explorado pelos autores clássicos do alienismo. A variedade dos tipos raciais brasileiros chama sua atenção desde o começo e a mestiçagem do país sugere um laboratório sobre a relação entre raças e alienação mental. Num esforço de tipificação, Jouin afirma que a sociedade brasileira, formada por um "povo jovem, entusiasta e sempre em festa" (1880, p. 240), seria composta por quatro diferentes raças: a "raça primitiva dos índios", os "filhos do país" (isto é, os mestiços de brancos e índios), os negros e os europeus. Jouin, citando Esquirol, Guislain, Moreau de Tours, e lembrando a 
afirmação do naturalista Alexander Von Humboldt sobre a presumível ausência de alienação mental entre índios da América do Norte e Central, reproduz uma visão consensual naquele momento: a grande incidência de alienação mental na Europa seria uma consequência do avanço da civilização e de suas exigências. Seria um mal dos países avançados. A incidência de alienação mental entre os povos primitivos seria menor, ou mesmo ausente. E este seria o caso brasileiro.

Portanto, a ausência de índios e a pequena quantidade de negros entre os internos do hospício é tomada por Jouin como uma confirmação dessa tese. Jouin afirma que "numa cidade onde eles (os negros) constituem, como dissemos, metade da população, ficamos surpresos de não encontrar mais de um deles em cada sete ou oito pacientes" (1880, p. 244); e que a maioria da população de internos consiste "de europeus recém-chegados, ou de cariocas de segunda, terceira ou, no máximo, quarta geração" (p. 215). O pensamento de Jouin expressa o crescente destaque dado às doutrinas constitucionalistas e raciais pelo alienismo na segunda metade do século XIX.

O calor brasileiro também é lembrado em diversas passagens. Jouin assinala que o Brasil é um dos países mais quentes do mundo. A relação entre o adoecer mental e o clima e ambientes (ares, águas e lugares) era extremamente importante de acordo com a visão neo-hipocrática dos alienistas do século XVIII e XIX. Textos de Pinel, Esquirol, Guislain e Moreau de Tours sublinham a importância da relação entre clima e semiologia na apresentação, evolução e tratamento da alienação mental. ${ }^{4}$

Jouin sublinha o grande número de internos com diagnóstico de mania, ${ }^{5}$ uma forma aguda de alienação, e o pequeno número de paralíticos gerais e de internos com outras formas crônicas de doença. Diz que a maioria dos casos de paralisia geral vistos por ele era de europeus recém-chegados. A seu ver, isso confirmaria a tese esquiroliana de que a loucura seria mais aguda e exuberante nos climas quentes. Os casos crônicos, isto é, os paralíticos gerais, seriam imigrantes recentes, ou descendentes diretos de europeus. Deste modo, Jouin conclui que a evolução da loucura seria menos incapacitante no Brasil.

4. Para aprofundamento das relações entre clima e alienação mental, ver Esquirol, 1838; Pinel, 1809; Guislain, 1826; Moreau de Tours, 1888.

5. Na classificação diagnóstica de Pinel e Esquirol, a mania é uma das formas gerais de alienação mental, caracterizada pela presença de um delírio geral que se estende sobre todos os objetos, relacionado à ideias vagas e incoerentes, que se sucedem sem ordem nem ligação. A mania em geral é acompanhada de grande excitação. Com frequência o delírio se exprime em imagens fantásticas, acompanhadas de paixões violentas, cólera, desdém, raiva ou furor. Nos dados levantados por Jouin, dentre 203 pacientes internados no Hospício de Pedro II, 141 receberam diagnóstico de mania. 
Segundo a concepção prevalente na época, a loucura seria rara nos climas tropicais. Porém, quando presente, mostrar-se-ia mais exuberante. O clima tropical influiria na apresentação dos quadros vistos no Hospício de Pedro II, tornando-os mais agudos, mais passageiros e, paradoxalmente, mais fatais. Jouin reproduz uma questionável observação feita por Moura e Câmara, de que dois terços dos alienados internados no asilo "eram curados ou morriam em pouco tempo", como uma confirmação da maior letalidade e curabilidade da mania no Rio de Janeiro. Até o fato de haver muitas celas-fortes no hospício é invocado como argumento por Jouin para caracterizar a excepcional agitação que a mania exibiria sob o calor tropical.

Jouin também afirma que a hipótese relacionando o aumento dos casos de alienação mental ao avanço da civilização seria insuficiente para explicar a aparente "imunidade", em suas palavras, de índios e negros à alienação mental no Brasil. Defende a aplicação de uma hipótese adicional, a do elemento racial. Segundo Jouin, essa hipótese teria sido subdimensionada até então pelo alienismo. A apresentação diferente dos quadros de alienação mental no Brasil, aliada ao fato de negros e índios serem poupados do acometimento, apontaria para um elemento da raça, capaz de proteger os povos primitivos das formas crônicas e incapacitantes de loucura vistas na Europa.

\section{O olhar eurocêntrico}

Os trabalhos de Rey e Jouin estão de acordo quanto à pequena presença de negros e escravos internados no Hospício de Pedro II. ${ }^{6}$ Ambos assinalam que o número de negros internados no hospício, escravos ou não, era surpreendentemente baixo em relação ao retrato étnico do país como um todo. Brancos e europeus predominam na população de doentes e os autores mostram-se intrigados com esse fato. Rey e Jouin partem do princípio de que a população de internos é o retrato fiel dos doentes existentes no país - isto é, no Hospício de Pedro II estariam internados todos aqueles que deveriam sê-lo. O que aparece inicialmente como uma constatação descritiva gera, a seguir, uma especulação, em especial no

6. As categorias "negros" e "escravos" são usadas, muitas vezes, como equivalentes por Rey e Jouin. O trabalho de Rey, por exemplo, refere-se aos pacientes naturais do país, indistintamente, como "brasileiros", não especificando sua cor. É provável que boa parte da população dos chamados nacionais fosse composta por mestiços, em razão as características da sociedade brasileira. 
texto de Jouin, sobre a etiologia da alienação mental, em sua relação com as características raciais dos alienados.

Jouin não percebe que, naquele momento, o Hospício de Pedro II é um projeto voltado para as elites ${ }^{7}$ brasileiras. Para o que de branco e europeu vicejava entre nós. Que o tratamento era caro e poucos eram internados como indigentes. O pequeno número de negros e escravos, antes de expressar uma característica racial, expressa uma variável social. Para os proprietários de escravos, interná-los numa instituição médica significava gastos econômicos injustificáveis. $\mathrm{O}$ abandono dos escravos doentes era a regra. E, ademais, era mais razoável comprar escravos novos e livrar-se dos doentes do que investir no tratamento de um escravo improdutivo. É preciso lembrar que a compra e venda de escravos era a atividade econômica mais lucrativa do país. Mais do que os frutos diretos do seu trabalho.

$\mathrm{O}$ artigo de Jouin exprime seu fascínio em relação à sociedade multirracial e escravocrata que se descortina diante de seus olhos. Jouin, porém, usa os dados obtidos para construir hipóteses que confirmam uma série de paradigmas consensuais e etnocêntricos de seu campo de conhecimento. A surpresa e a estranheza despertadas pelo objeto de investigação servem para referendar, de antemão, hipóteses e teorias admitidas como válidas em seu campo de conhecimento. Hipóteses que trazem a marca de um olhar eurocêntrico.

\section{Uma metáfora carnavalizada}

Num esforço final de defesa da administração de Moura e Câmara, Jouin termina seu artigo narrando um episódio no qual o diretor destina um trono, enfeitado com bandeiras brasileiras, a uma paciente megalômana que dizia ser a

7. Aqui é importante destacar que, se o projeto do Hospício de Pedro II permanece essencialmente ligado às elites rurais e mercantis da Corte até o final do Império, é a clientela dessa elite, não obstante, formada majoritariamente por indivíduos provenientes das camadas médias da população fluminense, que passa a ocupar progressivamente o espaço do hospício à medida que o período imperial se aproxima do fim. Quanto aos patronos dessa mesma elite, estes tendem a recorrer às Casas de Saúde privadas - tais como Dr. Eiras e São Sebastião que se desenvolvem a partir dos anos 1860, oferecendo maior respeitabilidade, privacidade e requintes de hotelaria. A proletarização da população do hospício terá de aguardar o surgimento da República, que determina a reversão do patrimônio do agora chamado Hospício Nacional de Alienados, que se torna laico e caminha para a completa medicalização de seu projeto institucional asilar. 
Imperatriz do Brasil. A paciente ali permanecia, sentada, recebendo as homenagens dos internos e visitantes que circulavam pelo hospício. Mesmo reconhecendo que tal medida não constitui um meio de tratamento, ${ }^{8}$ Jouin aplaude o caráter humanitário e a simpatia do gesto de Moura e Câmara. A imagem de uma paciente vestida de Imperatriz, reconhecida como rainha pelo gesto espontâneo de um médico à procura de alguma ação prática endereçada à alienação mental, recebendo o beija-mão dentro do Hospício de Pedro II, no suntuoso edifício erguido como símbolo de afirmação política, científica e filantrópica do Império brasileiro, cenário durante décadas de uma renhida disputa de poder entre ciência e religião, assume desse modo um valor simbólico. A cena reflete, numa espécie de metáfora carnavalizada, as diferentes contradições da criação da primeira instituição psiquiátrica no Brasil.

\section{Referências}

Agassiz, L.; Agassiz, E. A Journey in Brazil. Boston: Ticknor and Fields, 1869.

Almanak Laemmert. Almanak Administrativo, Mercantil e Industrial da Corte do Rio de Janeiro. Rio de Janeiro, 1877.

Andrade, N.F. Memórias. In: Anais Brasilienses de Medicina. Rio de Janeiro: Tomo 31, págs. 4, 156, 311 e 488 (1879-1880); Tomo 32, págs. 18, 141 e 255 (1880-1881).

Azevedo, M. O Rio de Janeiro: sua história, monumentos, homens notáveis, usos e curiosidades. Rio de Janeiro: Ed. Brasiliana, 1969.

BERTICHEM, P.G. O Rio de Janeiro e seus arrabaldes. Rio de Janeiro: Kosmos Editora, 1976.

BRAndẽo, J.C.T. Os alienados no Brasil. Imprensa Nacional (1886). Republicado in Arquivos Brasileiros de Neuriatria e Psiquiatria. Rio de Janeiro, v. 39, n. 2, p. 60$101,1956$.

Calmom, P. O Palácio da Praiua Vermelha (1852-1952). Rio de Janeiro: Ed. Universidade do Brasil, 1952.

CAstel, R. A Ordem Psiquiátrica: a Idade de Ouro do Alienismo. Rio de Janeiro: Graal, 1978.

Costa, E.V. Da Monarquia à República: momentos decisivos. São Paulo: Unesp, 1998.

8. Pelos princípios do tratamento moral pineliano, recursos teatrais como este poderiam ser empregados, mas como uma forma de confrontar o alienado com o próprio desvario, para provar-lhe a falsidade de suas crenças. Não como uma confirmação de sua crença delirante. 
EsQuirol, J-É. Folie. In: Dictionnaire des Sciences Médicales - Tome XVI. Paris: CLF Panckoucke Editeur, 1816.

Des maladies mentales: considérées sous les rapports medical, hygiénique et médico-legale - Vol. 1. Paris: J. B. Baillière, 1838.

Guislain, J. Traité sur l'alienation mentale et sur les hospices des alienés. Tome 2. Amsterdan: J. Van Der Hey et fils, 1826.

Jouin, F. Une Visite a L'asile de Pedro II a Rio de Janeiro (Brésil). Annales MédicoPsychologiques. Tome 3. Paris: Masson, 1880. p. 237-249.

Lopes, C. Notícia histórica da assistência a psicopatas no Distrito Federal. Arquivos Brasileiros de Neuriatria e Psiquiatria, Rio de Janeiro, v. 39, n. 2, p. 79-118, 1939.

Moreau, P. (De Tours). De la folie chez les enfants. Paris: J. B. Baillière, 1888.

Pinel, P. Traité médico-philosophique sur l'aliénation mentale. Paris: Brosson, 1809.

Rego, J. P. (Barão do Lavradio). Discurso Pronunciado pelo Presidente da Academia, Barão do Lavradio, em Sessão Magna de 30 de Junho de 1878, com o Fim de Provar a Conveniência do Estudo das Moléstias Mentais. In: Anais Brasilienses de Medicina, Tomo XXX, n. 1, jun./jul.), 1878.

Rego Filho, J. P. Relatório dos Trabalhos Acadêmicos de 30 de junho de 1875 a 30 de junho de 1876. Apresentado à Academia Imperial de Medicina em Sessão Magna do dia 30 de junho de 1879. Rio de Janeiro: Tipografia de E. \& H. Laemmert, 1879.

Rey, P-M. L’hospice Pedro II et les alienés au Brésil. Annales Médico-Psychologiques. Paris: Massom, 1875. p. 75-98.

Schwarcz, L. O espetáculo das raças: cientistas, instituições e questão racial no Brasil. Rio de Janeiro: Te Corá, 1998.

TeIXeIra, M.O. Deus e a ciência na Terra do Sol: o Hospício de Pedro II e a Constituição da Medicina Mental no Brasil. 1998. Tese (Doutorado). IPUB/UFRJ, 1998.

Teixeira, M.O.; Silva Filho, J.F. A Psiquiatria e a Universidade no Brasil: Nascimento, Ciência e Identidade Nacional. In: 1968 e a Saúde Mental. Rio de Janeiro: Contra Capa, 2008.

\section{Resumos}

(The origins of insane asylums in Brazil: two pioneer articles on Hospício de Pedro II (Pedro II Insane Asylum, Rio de Janeiro)

This article discusses two important documents in Brazilian psychiatric history. One was written by Phillipe-Marius Rey (1875) and entitled "L'hospice Pedro II et les 
Alienés au Brésil." It described the operations of the Pedro II Asylum, located in Rio de Janeiro, which was the first psychiatric institution in Brazil. The second document was "Visite a L'asile de Pedro II a Rio de Janeiro," by François Jouin (1880). In these texts the historical context of its founding and initial operations of the asylum are analyzed. Its establishment is related to the political realities of the 19th century. Aspects concerning organization of the treatment of the insane in Brazil, and society's racial characteristics there are mentioned.

Key words: Pedro II Asylum, insane asylums, history of psychiatry in Brazil, voyage narratives

(Les origines de l'aliénisme au Brésil: deux articles pionniers sur l'Hospice Pedro II)

Cet article analyse deux études qui, de façon inédite, ont décrit le fonctionnement de l'Hospice Pedro II, la première institution psychiatrique brésilienne: "L'Hospice Pedro II et les aliénés au Brésil», de Marius-Philippe Rey (1875), et «Visite à l'Asile Pedro II à Rio de Janeiro», de François Jouin (1880). Le contexte historique de la création de l'hospice, ainsi que son fonctionnement initial sont analysés. Sa construction est corrélée à l'affirmation politique du Second Règne. Des aspects concernant l'organisation de l'aliénisme au Brésil et les caractéristiques raciales de la société brésilienne y sont traités.

Mots clés: Hospice Pedro II, aliénisme, histoire de la psychiatrie au Brésil, narratives de voyage

(Los orígenes del alienismo en Brasil: dos artículos sobre el Hospício Pedro II)

El artículo analiza dos estudios que, por primera vez, han descrito el funcionamiento del hospicio Pedro II, la primera institución psiquiátrica en Brasil: "L’hospice Pedro II et les alienés au Brésil", de Phillipe-Marius Rey (1875); y "Visite a L'asile de Pedro II a Rio de Janeiro", de Francois Jouin (1880). Se analiza el contexto histórico de la creación del hospicio y su funcionamiento inicial. Su construcción se relaciona con la afirmación política del Segundo Reinado. Además se abordan aspectos que tienen que ver con la organización del alienismo y con las características raciales de la sociedad brasileña.

Palavras claves: Hospicio Pedro II, alienismo, historia de la psiquiatría en Brasil, narrativas de viaje

(Die Ursprünge der Studien über Geistesgestörtheit in Brasilien: Zwei große Pionierbeiträge über die psychiatrische Klinik PEDRO II)

In diesem Beitrag werden zwei Studien diskutiert, die erstmalig die Arbeit in der psychiatrischen Klinik PEDRO II, der ersten psychiatrischen Anstalt in Brasilien, beschrieben haben. L'hospice Pedro II et les Alienés au Brésil, von Phillipe-Marius Rey (1875); und Visite a L'asile de Pedro II a Rio de Janeiro, von François Jouin (1880). Es 
werden der geschichtliche Rahmen der Gründung der Anstalt und ihr anfänglicher Betrieb untersucht. Der Bau der Anstalt wird in Zusammenhang mit der politischen Affirmation des Zweiten Königreichs gebracht. Es werden Aspekte bezüglich der Organisation von Geistesgestörtheiten in Brasilien und der verschiedenen Aspekte der Rassen der brasilianischen Gesellschaft angesprochen.

Schlüsselwörter: Psychiatrische Anstalt Pedro II, Geistesgestörtheit, Geschichte der Psychiatrie in Brasilien

Citação/Citation: TeIXeIRA, M.O.L.; Ramos, F.A.DE C. As origens do alienismo no Brasil: dois artigos pioneiros sobre o Hospício de Pedro II. Revista Latinoamericana de Psicopatologia Fundamental, São Paulo, v. 15, n. 2, p. 364-381, jun.2012.

Editor do artigo/Editor: Prof. Dr. Paulo Dalgalarrondo e Profa. Dra. Ana Maria G. Raimundo Oda

Recebido/Received: 5.4.2012 / 4.5.2012 Aceito/Accepted: 15.4.2012 / 4.15.2012

Copyright: () 2009 Associação Universitária de Pesquisa em Psicopatologia Fundamental/ University Association for Research in Fundamental Psychopathology. Este é um artigo de livre acesso, que permite uso irrestrito, distribuição e reprodução em qualquer meio, desde que o autor e a fonte sejam citados / This is an open-access article, which permits unrestricted use, distribution, and reproduction in any medium, provided the original author and source are credited.

Financiamento/Funding: Os autores declaram não ter sido financiados ou apoiados / The authors have no support or funding to report.

Conflito de interesses/Conflict of interest: Os autores declaram que não há conflito de interesses / The authors declares that has no conflict of interest.

\section{Manoel Olavo Loureiro Teixeira}

Psiquiatra; doutor em psiquiatria pelo Instituto de Psiquiatria da Universidade Federal do Rio de Janeiro - IPUB/UFRJ (Rio de Janeiro, RJ, Br); pesquisador do Instituto de Pesquisa Clínica Evandro Chagas-IPEC/Fiocruz (Rio de Janeiro, RJ, Br); psiquiatra do Instituto de Psiquiatria da Universidade Federal do Rio de Janeiro - IPUB/UFRJ (Rio de Janeiro, RJ, Br).

Praça Radial Sul, 87/203 - Botafogo

22260-070 Rio de Janeiro, RJ, Br

e-mail: manoelolavo@gmail.com

\section{Fernando A. da Cunha Ramos}

Psiquiatra; presidente do Centro de Estudos do Instituto Municipal Philippe Pinel (Rio de Janeiro, RJ, Br); coordenador da Escola de Saúde Mental do Rio de Janeiro (Rio de Janeiro, RJ, $\mathrm{Br})$.

Rua Professor Estelita Lins, 90 - Laranjeiras

22245-150 Rio de Janeiro, RJ, Br

e-mail: facramos@terra.com.br 